\title{
CENÁRIO DO GERENCIAMENTO DOS RESÍDUOS DA CONSTRUÇÃO E DEMOLIÇÃO (RCD) EM UBERABA-MG
}

\section{Scenario of waste management of construction and demolition (CDW) in Uberaba, Minas Gerais (Brazil)}

\author{
Vinícius Arcanjo da Silva, \\ Engenheiro Ambiental, Prefeitura Municipal de Uberaba \\ viniciusarcanjo@live.com \\ André Luís Teixeira Fernandes, \\ Prof. Dr. Universidade de Uberaba. Bolsista CNPq \\ andrefernandes@uniube.br
}

Artigo recebido em 23/03/2012 e aceito para publicação em 29/05/2012

RESUMO: Em alguns municípios, os resíduos da construção civil representam $60 \%$ do montante de lixo que é gerado nos centros urbanos. A cidade de Uberaba convive com significativos impactos ambientais provocados pela não gestão dos resíduos construtivos. No município, existem áreas altamente degradadas pela destinação inadequada dos Resíduos da Construção e Demolição (RCD) ou Resíduos da Construção Civil (RCC). A falta de gerenciamento desses resíduos afeta a cidade nos aspectos econômico, sociais e principalmente ambientais. Neste trabalho, foram levantados os principais impactos ambientais que ocorreram devido à falta de gestão dos RCD na cidade de Uberaba. Foram abordados alguns pontos como: a eficiência dos "ecopontos”, degradação da área da Pedreira de Léa e riscos para a saúde pública da cidade. Ainda foram discutidos os motivos que levam à não gestão dos RCD e o que tem sido feito para que futuramente esta gestão venha ser implantada. Este trabalho foi composto por revisão bibliográfica associada a visitas in loco das áreas afetadas pela destinação inadequada dos RCD. Desta forma, este trabalho propôs soluções para redução dos impactos ambientais causados pelos RCD gerenciados de maneira inadequada em Uberaba, visando obter melhorias para a saúde pública e contribuindo para a sustentabilidade ambiental da cidade.

Palavras-chave: Área degradada. Saúde pública. Impacto ambiental.

ABSTRACT: In some municipalities, construction waste accounts for $60 \%$ of the monamount of waste that is generated in urban centers. The city of Uberaba lives with significant environmental impacts caused by not constructive waste management. In the city, there are areas highly degraded by improper disposal of Construction and Demolition Waste (CDW) or Civil Construction Waste (CCW). The lack of these waste management affects the city in the economic, social and especially environmental. This work, raised the main environmental impacts that have occurred due to the lack of management of CDW in the city of Uberaba. Some points were discussed as: the efficiency of "ecopoints", degradation of the Quarry area of Lea and risks to public health of the city. It is still discussed the reasons of not Construction and Demolition Waste management and what has been done to this management be implemented. This work consists of reviewing the literature associated with on-site visits of areas affected by inadequate allocation of CDW. So, this work proposes solutions to reduce environmental impacts caused by improperly managed CDW in Uberaba. In order to obtain improvements to public health and contributions to environmental sustainability in the city.

Keywords: Degraded area. Public health. Environmental impact. 


\section{INTRODUÇÃO}

Os resíduos gerados durante a construção ou demolição são de extrema importância no montante que é produzido nos centros urbanos. Estes resíduos constituem uma parte representativa do total de "lixo" gerado nas cidades.

Quando o tema é resíduo da construção civil ou, tecnicamente, Resíduos da Construção e Demolição (RCD), deve ser tratado com aprimorado conhecimento técnico, pois esses materiais são, na maioria das vezes, matéria prima para agregados de ótima qualidade, podendo ser utilizados em outras etapas do processo construtivo. A construção civil brasileira tem se caracterizado pela introdução de novas tecnologias, no entanto, métodos arcaicos ainda são utilizados devido ao acelerado crescimento do setor e falta de qualificação da mão de obra. Utilizar métodos ultrapassados ocasiona sempre desperdício, no caso da construção civil, prejuízo e geração de um grande volume de resíduos. Além de reduzir o volume de RCD produzido é necessária a implantação de um sistema eficiente de reciclagem. Para Evangelista et. al (2010) a reciclagem de RCD no Brasil encontra-se em atraso se comparado aos países europeus. Ainda Evangelista et. al (2010) afirma que:

A implantação de usinas de reciclagem com produção regular e padrões de qualidade definidos ainda não se transformou em rotina adotada pelas prefeituras, nem pela iniciativa privada. Apesar disso, alguns municípios estão procurando se organizar para adotar uma política de gerenciamento de seus resíduos sólidos com o objetivo de transformá-los, de forma empresarial, em agregados reciclados (EVANGELISTA, 2010 p. 27 apud LEVY, 2001).

Uberaba, cidade com 295.988 habitantes, segundo o senso do IBGE (2010), não está em situação satisfatória quanto ao gerenciamento dos $\mathrm{RCD}$, pois, a cidade ainda não conta com nenhum programa efetivo para destinação dos resíduos construtivos gerados no município. O destino inadequado de resíduos da construção foi a responsável pela degradação da área da Pedreira Jardim Espírito Santo. Atualmente, a destinação inadequada de RCD tem sido o principal agente destruidor da área da Pedreira de Léa. Tanto $\mathrm{a}$ área da Pedreira Jardim Espírito Santo quanto a área da Pedreira de Léa são Áreas de Preservação Permanente - APP's. As APP's são áreas com função ambiental conforme o Código Florestal (Lei 4.771 de 15 de Setembro de 1965) e, portanto, merecem uma maior atenção e devem ser protegidas. Ambas as áreas degradadas das pedreiras ficam às margens do Rio Uberaba, o principal responsável pelo abastecimento de água da cidade. As áreas das Pedreiras foram utilizadas não somente para o lançamento de resíduos da construção civil como também para o lançamento de resíduos domiciliares, hospitalares e até mesmo de origem industrial.

A partir do ano de 2002, foram publicadas leis e resoluções que normatizaram a gestão dos resíduos da construção. No entanto, não são aplicadas na sua totalidade no que se refere à gestão dos resíduos construtivos gerados em Uberaba. Neste trabalho, serão discutidos os principais impactos ambientais causados pela não gestão dos resíduos da construção civil da cidade. Serão levantadas as principais leis e resoluções além de algumas normas técnicas sobre o assunto sendo propostas soluções para o problema.

Considerando os graves problemas detectados, o presente trabalho apresenta uma análise crítica sobre as possíveis causas da persistência da deposição e destinação inadequada de RCD em logradouros públicos e APP's. Também é levantada a possível solução para o problema que afeta a cidade nos aspectos sociais, econômicos e principalmente ambientais.

\section{METODOLOGIA DA PESQUISA}

O presente estudo foi realizado entre os anos de 2010 e 2011 com visitas aos principais pontos de descarte de RCD da cidade de Uberaba. Devido à escassez de dados sobre o tema RCD no Município, a maior parte deste trabalho foi produzida a partir de visitas in loco e com levantamentos sobre a legislação referente ao tema.

Para esta pesquisa, foram formuladas algumas perguntas que originaram a discussão presente. A pergunta inicial foi: a cidade de Uberaba faz uma

Soc. \& Nat., Uberlândia, ano 24 n. 2, 333-344, mai/ago. 2012 
gestão eficiente dos seus RCD? A segunda pergunta: Quais os principais impactos ambientais causados pelos RCD na cidade de Uberaba? O terceiro e último questionamento foi: é possível melhorar a forma de gerir os RCD que Uberaba produz? Visando responder a estes três questionamentos foi possível desenvolver esta pesquisa.

A legislação existente é ressaltada neste trabalho visando questionar o porquê do não cumprimento das leis pelo Município. Para registro das visitas, foi utilizada uma máquina fotográfica e prancheta para anotação das situações que mereceram destaque. Alguns impactos ambientais não serão relatados neste trabalho, pois, são de menor significância e em pouco contribuíram para o desenvolvimento do estudo. Os ecopontos que são locais onde a Prefeitura de Uberaba faz o recolhimento de pequenos volumes de RCD serão abordados somente em alguns aspectos, pois, a problemática é extensa e complexa, merecedora de um trabalho exclusivo. A captação de RCD com ecopontos não obteve sucesso e, portanto, passarão por processo de modificação e até de remoção de alguns destes locais que se encontram em áreas ambientalmente frágeis. Todos os dados coletados foram avaliados tendo como foco os impactos ambientais provocados na cidade de Uberaba.

\section{A TIPOLOGIA DOS RCD E A LEGISLAÇÃO}

Os Resíduos de Construção e Demolição RCD têm grande importância para a sociedade, principalmente neste período de franco desenvolvimento do setor construtivo em que o Brasil se encontra, devido aos Programas de Aceleração do Crescimento - PAC - 1 e 2. Os RCD apresentam volume expressivo mediante o montante de "lixo" que é gerado nos centros urbanos. Os resíduos são gerados em diversas etapas do processo construtivo desde a terraplanagem até a demolição da construção.

Segundo a Resolução do Conselho Nacional do Meio Ambiente - CONAMA, 307 de 5 de julho de 2002, a definição para Resíduos de Construção e Demolição - RCD:

...são os provenientes de construções, reformas, reparos e demolições de obras de cons- trução civil, e os resultantes da preparação e da escavação de terrenos, tais como: tijolos, blocos cerâmicos, concreto em geral, solos, rochas, metais, resinas, colas, tintas, madeiras e compensados, forros, argamassa, gesso, telhas, pavimento asfáltico, vidros, plásticos, tubulações, fiação elétrica etc., comumente chamados de entulhos de obras, caliça ou metralha (CONAMA, 2002 p. 1).

A Resolução CONAMA307 (2002) foi elaborada visando conforme seu artigo $1^{\circ}$ "Estabelecer diretrizes, critérios e procedimentos para a gestão dos resíduos da construção civil, disciplinando as ações necessárias de forma a minimizar os impactos ambientais".

Os RCD são em quase sua totalidade compostos por materiais de característica sólida e enquadrados conforme Norma Brasileira-NBR- 10.004 de 30 de novembro de 2004 na classe II B - inertes.

De acordo com a NBR 10.004 (2004), os resíduos da classe II B- inertes são:

Quaisquer residuos que, quando amostrados de uma forma representativa, segundo a ABNT NBR 10.007, e submetidos a um contato dinâmico e estático com água destilada ou desionizada, à temperatura ambiente, conforme ABNT NBR 10.006, não tiverem nenhum de seus constituintes solubilizados a concentrações superiores aos padrões de potabilidade de água, excetuando-se aspecto, cor, turbidez, dureza e sabor, conforme anexo G (ABNT NBR10.004, 2004 p. 11).

Segundo Careli (2008), o setor da indústria da construção civil consome cerca de $50 \%$ de todos os recursos naturais além de gerar volume elevado de resíduos; cerca de $60 \%$ do "lixo" que é produzido diariamente nas cidades tem origem do setor da construção civil.

Para Evangelista et. al (2010), “...ainda são restritas em muitos municípios as alternativas para a destinação ambientalmente correta dos RCC". O novo desafio das cidades tem sido a destinação adequada dos RCD em meio ao cenário de falta de estrutura para gerir resíduos. 
Os RCD são vistos até então, pela sociedade, como lixo que gera despesas, aumentando o custo final das obras. Porém, este "lixo" tem ganhado valor no mercado e o que antes era estorvo, está se tornando "moeda" de negociação em meio ao setor construtivo. Os resíduos que têm maior valor no mercado são os resíduos enquadrados na Classe A segundo a Resolução 307 (2002) do CONAMA. Segundo Souza et. al. (2008) a reciclagem e o reaproveitamento dos RCD se destacam como alternativas alinhadas aos novos conceitos como a sustentabilidade, buscando valorizar os materiais descartados nas obras de engenharia. Desta forma é atribuída a estes resíduos a condição de material nobre, ao invés de simplesmente lançá-los no meio ambiente.

No art. $3^{\circ}$ da Resolução 307 (2002) do CONAMA são classificados os RCD da seguinte maneira:

Art. $3^{\circ}$ Os resíduos da construção civil deverão ser classificados, para efeito desta Resolução, da seguinte forma:

I - Classe A - são os resíduos reutilizáveis ou recicláveis como agregados, tais como:

a) de construção, demolição, reformas e reparos de pavimentação e de outras obras de infra estrutura, inclusive solos provenientes de terraplanagem;

b) de construção, demolição, reformas e reparos de edificações: componentes cerâmicos (tijolos, blocos, telhas, placas de revestimento etc.), argamassa e concreto;

c) de processo de fabricação elou demolição de peças pré-moldadas em concreto (blocos, tubos, meio-fios etc.) produzidas nos canteiros de obras;

II - Classe B - são os resíduos recicláveis para outras destinações, tais como: plásticos, papel/papelão, metais, vidros, madeiras e outros;

III - Classe C - são os resíduos para os quais não foram desenvolvidas tecnologias ou aplicações economicamente viáveis que permitam a sua reciclagem/recuperação, tais como os produtos oriundos do gesso;

IV - Classe D: são resíduos perigosos oriundos do processo de construção, tais como: tintas, solventes, óleos e outros ou aqueles contaminados ou prejudiciais à saúde oriundos de demolições, reformas e reparos de clínicas radiológicas, instalações industriais e outros, bem como telhas e demais objetos e materiais que contenham amianto ou outros produtos nocivos à saúde (nova redação dada pela Resolução $n^{\circ}$ 348/04) (CONAMA 307, 2002 p. 2).

Seguida a classificação estabelecida pela Resolução 307 (2002), sendo realizada a segregação na fonte, se torna fácil o manuseio dos RCD e futura destinação dos mesmos. A sua segregação na fonte de origem é o primeiro e um dos mais importantes passos para a gestão ambiental e tecnicamente correta destes resíduos.

A legislação que abrange o tema "resíduos sólidos" era muito escassa até a década de 90 , pois, a sociedade ainda conseguia conviver com os transtornos causados pelo destino inadequado. A partir do momento que os resíduos começaram a causar problemas de saúde pública devido à sua deposição e disposição de maneira inadequada na área do perímetro urbano e a provocar graves impactos ambientais, foi necessária a ampliação da legislação específica para o tema. Em 5 de julho de 2002, o CONAMA instituiu a resolução 307 que estabeleceu diretrizes, critérios e procedimentos para a gestão de resíduos da construção e demolição. Apesar de a Resolução ter entrado em vigor em 02 de janeiro de 2003 e ter estabelecido o prazo de 18 meses para a efetiva implementação pelos municípios, 8 anos depois a cidade de Uberaba ainda não implantou seu sistema de gerenciamento de RCD conforme a Resolução 307 do CONAMA.

Segundo Careli (2008), a mobilização em torno da questão do gerenciamento dos RCD promovida pelo CONAMA decorreu da percepção pela sociedade da urgência em estabelecer condições para que seja possível manejar e destinar os RCD adequadamente, sendo que os efeitos provocados pela dispersão dos entulhos nas cidades são significativos.

Um grande avanço no gerenciamento dos RCD em Uberaba foi a publicação da Lei 10.876 de 11 de dezembro de 2009, para implantação do sistema de gestão municipal dos resíduos da construção

Soc. \& Nat., Uberlândia, ano 24 n. 2, 333-344, mai/ago. 2012 
e demolição, no entanto, até o primeiro semestre de 2011 pouca coisa havia saído do "papel".

Outro marco importante para o gerenciamento de RCD só que, em âmbito nacional, foi a Política Nacional de Resíduos Sólidos (Lei 12.305) de 02 de agosto do ano de 2010, alterando a Lei ${ }^{\circ} 9.605$ de 12 de fevereiro de 1998. A Política Nacional de Resíduos Sólidos sofreu grande resistência por parte do setor privado principalmente quanto à política reversa, mas rapidamente esta resistência foi vencida, pois, a sociedade cobra mais a cada dia uma produção ambientalmente racional.

\section{GERENCIAMENTO DE RCD EM UBERABA}

Segundo Schneider (2003), da extração de matéria prima para a indústria da construção civil é originada uma massa de resíduos igualmente responsável por impactos ambientais e sanitários.

$O$ gerenciamento de RCD é algo a ser pensado a curto, médio e em longo prazo, envolvendo não somente a iniciativa privada, mas também o Poder Público e a sociedade em geral. Depositar e destinar de maneira correta os RCD é uma ação que trará benefícios não somente ambientais, mas também sociais, econômicos e melhorias para a saúde pública.

Segundo Botta (2011):

No município de Uberaba está em fase de implantação desde 2008 o Plano Integrado de Gerenciamento de Resíduos da Construção Civil, porém enfrentando inúmeras dificuldades, entre elas a pouca importância $e$, até mesmo o descaso, dado ao assunto em especial pelos grandes geradores de resíduos (BOTTA, 2011 p. 2).

A implantação do gerenciamento dos RCD em Uberaba tem se mostrado pouco eficiente tanto pela falta de interesse dos grandes geradores (BOTTA, 2011), quanto pela falta de interesse político. A falta de iniciativa política é mais grave que a ausência de interesse por parte dos grandes geradores, afinal, quem deve normatizar e fiscalizar o desenvolvimento da cidade é o Poder Público destacando-se o municipal. Decisões incipientes (lançamento de RCD em APP's, destinação de RCC em pedreiras abandonadas, etc) quanto ao gerenciamento dos RCD em Uberaba foram tomadas em outros momentos, o que gera resultados desastrosos no presente. A falta de interesse pelo assunto e de planejamento são os responsáveis por resultados como a destinação de RCD na Pedreira Jardim Espírito Santo (às margens do Rio Uberaba) e recentemente na Pedreira de Léa. Um fator agravante é que a Pedreira de Léa encontra-se a montante da captação de água que é realizada pelo Município no Rio Uberaba, colocando em risco a saúde da população.

O resultado da utilização da Pedreira de Léa como destino final de RCD pode ser observado na Figura 1. Os funcionários da Prefeitura de Uberaba tiveram que improvisar um barramento para conter o chorume dissolvido em água que escoava da cava da Pedreira de Léa para a calha do Córrego Lageado.

Figura 1 - Lagoa de chorume dissolvido em água na cava da Pedreira de Léa

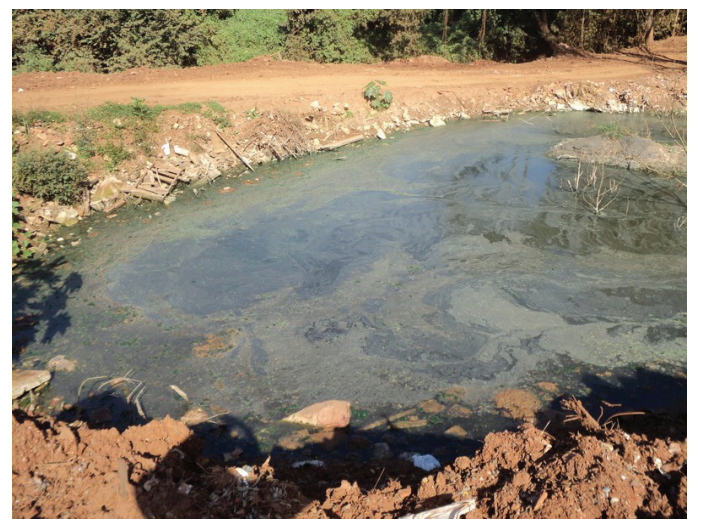

Foto dos autores (2011). 
Mesmo demonstrando interesse em solucionar o problema de escoamento de chorume da Pedreira de Léa para o Córrego Lageado, os funcionários da Prefeitura Municipal de Uberaba não obtiveram sucesso. Após o barramento para retenção do chorume ilustrado na Figura 1 parte do líquido contaminante atravessou a barreira confeccionada com terra e resíduos sólidos de diferentes origens.

Poucos metros à frente do local onde o chorume entra no Córrego Lageado e este deságua no Rio Uberaba em local a montante da captação de água da cidade. Este chorume é proveniente de resíduos orgânicos (que devido à falta de fiscalização e segregação na fonte, são destinados junto com RCD), produtos químicos utilizados na construção civil e lixo doméstico lançados indevidamente na Pedreira de Léa.

Depois de anos de protelação, em 27 de maio de 2011, foi realizada uma reunião referente ao Inquérito Civil Público 0701.08.000412-3 - MP/MA de 06 de maio de 2008, instaurado após denúncias da população sobre os resíduos descartados na Pedreira de Léa sem a devida segregação. Na reunião estavam representantes da $1^{\text {a }}$ Promotoria de Justiça de Uberaba, Prefeitura Municipal e também do setor privado. Na reunião, ficou acordado que em 60 dias a partir daquela data de 27 de maio de 2011 a empresa responsável pelo aterro de RCD estaria em condições de entrar em operação para o recebimento dos resíduos da construção e demolição. Os 60 dias decorreram e a solução não foi encontrada permanecendo como destino para os RCD a cava da Pedreira de Léa.

Uberaba é um dos poucos municípios brasileiros a instituir uma Lei específica para a gestão de RCD. A Lei $\mathrm{n}^{\circ} 10.876$ instituiu o Sistema para a Gestão Sustentável de Resíduos da Construção Civil e Resíduos Volumosos. O sistema de gestão de RCD descrito na Lei 10.876 (2009) abrange todo o processo de destinação dos resíduos da construção e demolição desde a redução na sua geração até a destinação final.

No artigo $6^{\circ}$ da Lei 10.876 (2009), são descritos os constituintes do sistema de gestão para os resíduos da construção civil e demolição e também para os resíduos volumosos:

I - uma Rede de Pontos de Apoio para pequenos volumes de resíduos da construção civil e resíduos volumosos, implantada em bacias de captação de resíduos;

II - sistema Disque Coleta para Pequenos Volumes de acesso telefônico a pequenos coletores privados de resíduos da construção civil e resíduos volumosos;

III - uma Rede de Áreas para Recepção de grandes volumes (Áreas de Transbordo e Triagem, Áreas de Reciclagem e Aterros de Resíduos da Construção Civil);

$I V$ - ações para a informação e educação ambiental dos munícipes, dos transportadores de resíduos e das instituições sociais multiplicadoras, definidas em programa especifico; $V$ - ações para o controle e fiscalização do conjunto de agentes envolvidos, definidas em programa especifico;

$V I$ - ação de gestão integrada a ser desenvolvida por Núcleo Permanente de Gestão que garanta a unicidade das ações e exerça o papel gestor que é competência do Poder Público Municipal (CAMARA MUNICIPAL DE UBERABA, 2009 p. 4).

Após a reunião de 27 de maio de 2011, a Prefeitura Municipal de Uberaba deu início à elaboração de um Plano de Recuperação de Áreas Degradadas - PRAD visando à reabilitação da área da cava da Pedreira de Léa onde os resíduos foram lançados. A execução do PRAD só será possível quando estagnado o depósito de resíduos no local.

\section{Ecopontos}

Os ecopontos são locais definidos no perímetro urbano da cidade de Uberaba onde a população destina pequenos volumes de RCD. Os ecopontos foram implantados no ano de 2007 e desde suas implantações já eram considerados problemas para o gerenciamento dos resíduos construtivos. Botta (2011) relata a situação dos ecopontos no ano de 2007 ressaltando o não seguimento das normas para a implantação dos mesmos:

Por sua vez o município em 2007 já havia definido, por toda malha urbana, pontos de cap-

Soc. \& Nat., Uberlândia, ano 24 n. 2, 333-344, mai/ago. 2012 
tação para o pequeno gerador, denominados ecopontos, ou seja, iniciava-se a implantação do Programa Municipal de Gerenciamento de Resíduos da Construção Civil ampliando assim o sistema de limpeza urbana. Entretanto estes locais não seguiam ao especificado na Associação Brasileira de Normas Técnicas ABNT NBR 15112 e assim, mais uma vez os locais eram mal utilizados pela comunidade que, além de entulhos, depositam lixo domiciliar e todos os tipos de resíduos não permitidos (BOTTA, 2011 p. 9).
No dia 06 de setembro de 2011, foi realizada uma visita aos ecopontos em funcionamento na cidade. Não se objetivou levantá-los ou especificar cada um deles, mas sim entender o seu funcionamento. Porém, um fato chamou a atenção que foi a placa de informação que existe nos ecopontos (Figura 2). $\mathrm{Na}$ figura, consta um exemplo da placa do ecoponto situado na Rua Lupércio Ferreira Assunção, onde é dada permissão para a população destinar pequenos animais mortos ao ecoponto:

Figura 2 - Placa de informação dos ecopontos

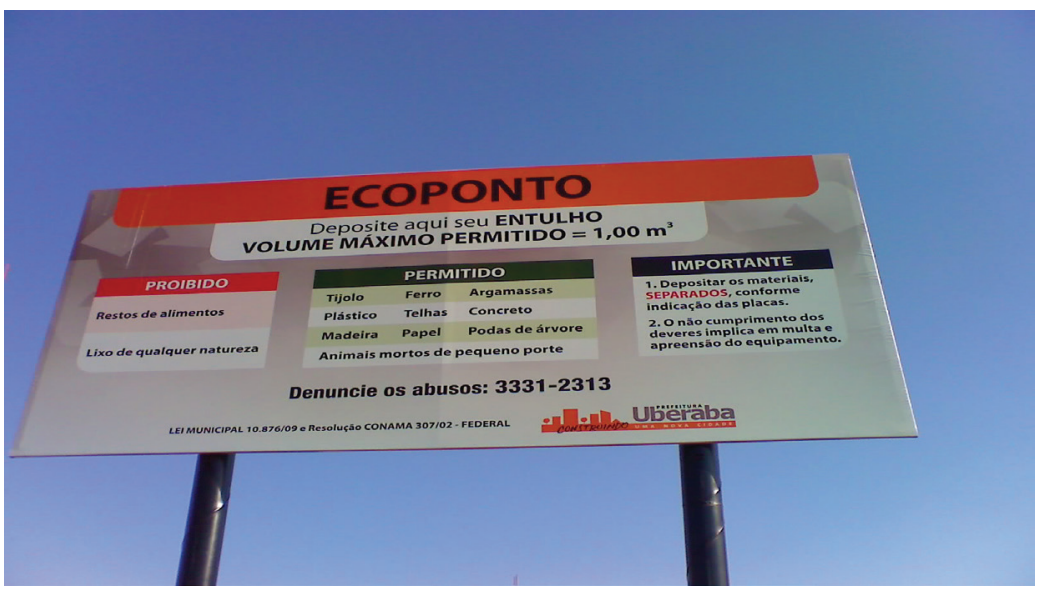

Foto dos autores (2011)

Na parte inferior central da placa, é feita referência à Resolução CONAMA 307 (2002). No entanto, foi verificado que todo o volume de resíduos captado nos ecopontos, sejam eles RCD ou não é destinado a cava da Pedreira de Léa. Isso gera uma situação contraditória, pois, segundo a placa informativa é realizada a separação e atendimento das especificações da Resolução 307 do CONAMA. De nada adianta realizar a separação conforme a Resolução se, no final, tudo é descartado sem o mínimo de utilização de técnica fazendo da Pedreira de Léa um grande "lixão a céu aberto". Outro fator preocupante é que os ecopontos estão recebendo resíduos eletrônicos que contém metais pesados entre outros contaminantes. $O$ cenário demonstra a falta de treinamento dos profissionais que trabalham nos locais. E o texto da placa infor- mativa deixa claro a falta de conhecimento do setor responsável pela estruturação destes locais de captação de RCD. Ainda existem ecopontos ou como serão denominados após término da estruturação "Pontos de Apoio" que não tem o mínimo de estrutura para o recebimento de RCD, alguns deles são simplesmente áreas sem ocupação que são utilizadas como depósito de resíduos.

O ecoponto da Rua Lupércio Ferreira Assunção além de ter problemas quanto a sua placa de informações também se encontra em uma área ambientalmente inadequada, uma vez que este ecoponto está acima de uma Área de Preservação Permanente-APP caracterizada pela presença de uma nascente. 


\section{O papel desempenhado pela população}

Além da falta de interesse político para a efetivação do gerenciamento de RCD em Uberaba, a população tem sua parcela de responsabilidade. Foi verificado que pessoas jogam os seus resíduos construtivos ao lado dos ecopontos e próximos às áreas inabitadas. Em alguns casos, existe a deposição de RCD realizada em contato com o cerceamento dos ecopontos só que na parte externa. Assim, é notória a falta de compromisso da população quanto à correta destinação dos resíduos e alguns casos também devido a falta de informação.

Para que a população aja de maneira correta, é necessário que o Poder Público faça a sua parte para que sirva de exemplo e em seguida implemente um sistema eficiente de educação ambiental focado no destino adequada de RCD. Os ganhos seriam enormes nos três níveis: econômico (os RCD podem ser comercializados como matéria prima de novas construções), social(a segregação dos RCD gera elevada demanda de mão de obra) e ambiental(limpeza do ambiente urbano e menor impactos sobre as APP's que são utilizadas como depósitos de RCD). Segundo Espinheira (2007) "...somos humanos e compreendemos muito bem do que somos capazes. O nosso saber precisa se tornar um instrumento de civilização, de respeito ao ser humano na perspectiva de que "um outro mundo é possível"... (ESPINHEIRA, 2007 p. 101).

De acordo com Viezzer (2007):

Em todos os lugares do planeta, as ações humanas que se sobrepuseram ao planejamento da natureza com forte impacto ambiental estão sendo repensadas, trazendo a necessidade urgente da formação da consciência ambiental e cidadã e a educação de pessoas/instituições a partir de principios e valores que orientam as ações na perspectiva da ética do cuidado para a sustentabilidade. Esta constatação nos remete a uma questão fundamental: de quem depende um novo presente e um novo futuro no planeta Terra e a quem deve dirigir-se a educação ambiental? (VIEZZER, 2007 p. 37).
É importante salientar que a população deve esclarecida quanto à necessidade de aplicação dos conhecimentos adquiridos. Os conhecimentos ambientais são inúteis se além de esclarecida quanto as questões ambientais as pessoas não forem sensibilizadas.

\section{IMPACTOS CAUSADOS PELA DEPOSIÇÃO E DESTINAÇÃO INADEQUADA DE RCD}

Deve-se reduzir a geração de RCD visando impactar menos o meio ambiente, o setor construtivo tem trabalhado para isso, porém demonstrado alguma dificuldade como afirma Careli (2008). A avaliação do ciclo de vida das construções possibilita identificar os fluxos de materiais e energia necessários durante a implantação até a desativação das respectivas obras. Porém, existem dificuldades para realizar a avaliação do ciclo de vida como de um edifício, por exemplo, pois, a vida útil geralmente longa (acima de 10 anos) e com enorme quantidade de materiais empregados (CARELI, 2008). Em visitas realizadas no mês de junho de 2011 a diferentes pontos dentro do perímetro urbano foi possível constatar que quanto mais baixo o padrão dos imóveis maior é o acúmulo de RCD em suas proximidades.

A deposição em locais inadequados de RCD sem a utilização de técnica (ver resolução 307/02 do CONAMA e ABNT NBR 10.004/04) é um problema que traz consequências significativas para a sociedade propiciando a proliferação de pragas urbanas (baratas, ratos, etc). A deposição dos RCD é o ato que parte dos geradores de resíduos da construção pratica, aguardando que o Poder Público dê a devida destinação aos resíduos.

No perímetro urbano da cidade de Uberaba, é possível encontrar vários locais com deposição de RCD, sendo necessária a remoção por parte do Poder Público destes entulhos. Os resíduos podem servir de atrativo para animais transmissores de doenças, que assim teriam acesso à proteção, água e alimento. Dentre os vetores que transmitem doenças, destaca-se o Aedes aegypti que é o transmissor da dengue.

A destinação dos RCD realizada de maneira inadequada é tão preocupante quanto a deposição em locais inapropriados. Esta afirmação se deve ao fato de que quando é realizada a destinação dos RCD,

Soc. \& Nat., Uberlândia, ano 24 n. 2, 333-344, mai/ago. 2012 
geralmente é feita em locais onde a população não convive com os mesmos e, portanto, não faz pressão para que alguma solução seja proposta pelo Poder Público ou mesmo iniciativa privada. O caso da Pedreira de Léa é um exemplo de destinação de RCD de maneira inadequada, uma vez que os resíduos foram destinados sem segregação ou mesmo sem o mínimo de fiscalização e identificação do tipo de material que estava sendo lançado. Geralmente, os RCD, quando destinados sem o devido planejamento, são lançados em áreas ambientalmente frágeis. A destinação de RCD em áreas ambientalmente frágeis se deve ao fato de que estas áreas não têm valor no mercado, logo são pouco monitoradas.

\section{ATUAÇÃO DO PODER PÚBLICO MUNICIPAL}

Para a implantação de um sistema municipal de gerenciamento de RCD, é necessário empenho do Poder Público Municipal e do setor privado. Por se tratar de "resíduos", a viabilidade econômica e social é questionada no momento da implantação do sistema de gerenciamento dos mesmos. No entanto, Botta (2011) demonstra que a implantação de um sistema de gerenciamento de RCD é viável desde que bem estruturada. Ao descrever o sistema dos pontos de captação e também o gerenciamento dos RCD da cidade de São José do Rio Preto - SP, Botta (2011) relata que:

Foi ainda implantada uma usina de reciclagem, para o processamento de 800 ton/dia de resíduo, cujo gerenciamento é de cooperativa que transforma o residuo classe A em agregado de diversas granulometrias que são utilizados na fabricação de equipamentos urbanos (tubos, bancos, mesas, blocos de concreto, pavimentos para praças e calçadas, guias e meios fios) bem como para preparo de vias para futura pavimentação e ainda para manutenção de estradas rurais. Estes materiais eram utilizados pela Prefeitura em parceria com a cooperativa. Até 2008, a cooperativa era fonte de sustento de 50 famílias e, mais recentemente foi noticiada a expansão da usina, devido ao sucesso da parceria, com a aquisição de mais um britador com capaci- dade 100\% maior que o existente (BOTTA, 2011 p. 16).

Desta forma, verifica-se que o gerenciamento de RCD é uma atividade que proporciona benefícios ambientais, econômicos e sociais.

Apesar de a cidade de Uberaba não ter um gerenciamento de RCD, verifica-se que há considerável progresso previsto para os próximos anos. No ano de 2011, encontrava-se em fase de instalação o aterro industrial e a implantação de empresas que irão dar o tratamento correto aos resíduos construtivos proporcionando que estes retornem a cadeia de produção. É importante ressaltar que a implantação de um sistema de gerenciamento de RCD é um procedimento que demanda um determinado período para sua efetivação. Esse período é o necessário para que a sociedade se adapte a destinar nos locais especificados seus RCD. Atualmente, os antigos "ecopontos" que eram locais para a deposição de RCD especificados pela Prefeitura Municipal de Uberaba estão sendo transformados em "pontos de apoio" que são unidades preparadas para receber estes resíduos adequadamente. Também estão sendo removidos os ecopontos que se encontravam em locais inadequados.

Diante do cenário da falta de estrutura para o gerenciamento dos RCD na cidade de Uberaba, o Poder Público Municipal tomou algumas medidas para melhorar a "imagem" negativa do Município quanto à gestão de RCD. Dentre essas medidas está a promessa de interrupção do lançamento de RCD na Pedreira de Léa, no entanto são apenas promessas de concreto nenhuma atitude foi verificada.

A proximidade da área da Pedreira de Léa com o perímetro urbano é preocupante, principalmente quanto à classificação dos resíduos que são destinados ao local. Bota (2011) afirma que:

Ocorre que a captação destes materiais, seja por meio de transportadores autônomos ou empresas especializadas e, até mesmo pelo Poder Público, não passa por nenhum tipo de segregação. Como a maioria das caçambas de recolhimento de entulhos ficam expostas em vias públicas e não há conscientização por parte da população, é muito grande a 
quantidade de lixo domiciliar depositado nas mesmas e também levados pela própria população, apesar do município contar com coleta de lixo em 100\% da malha urbana na freqüência de três vezes por semana. Verifica-se ainda a incidência de descarte de resíduo industrial, seja do tipo classe I ou classe II, que é notória (BOTTA, 2011 p. 8)

O distanciamento da área de deposição e tratamento dos RCD é um grande avanço para Uberaba. A nova área de destinação dos RCD situa-se a mais de $10 \mathrm{Km}$ da cidade e estando a mesma situada em áreas de atividades industriais altamente impactantes no meio ambiente e na sociedade.

A presença de resíduos classificados como Classe I segundo a ABNT NBR 10.004 (2004) é um fator que expõe a população de Uberaba a riscos de contaminação por metais pesados e tóxicos ao organismo humano que impactariam na saúde pública a curto, médio e longo prazo. Segundo Pinto (1999), a presença de resíduos perigosos (produtos ácidos, inflamáveis e outros) em meio aos RCD é baixa, mas que este aspecto não deve ser secundarizado (PINTO, 1999 p. 21). Mesmo sendo construído um novo aterro para RCD em Uberaba, é necessário avaliar a sua vida útil. Para Pinto (1999), o que mais se encontra nos municípios de médio e grande porte é a disposição adequada de RCD em locais de "bota foras" que são os aterros inertes. "Constitui o problema mais significativo na destinação dessa parcela dos resíduos o inexorável e rápido esgotamento das áreas designadas para disposição" (PINTO, 1999 p. 58).

\section{SISTEMA DE GERENCIAMENTO EFICIENTE PARA OS RCD DO MUNICÍPIODE UBERABA}

Para Leite (2001), ao se estudar a composição média dos resíduos construtivos, alguns fatores devem ser considerados: a tipologia construtiva que foi utilizada, quais as técnicas construtivas existentes e os materiais disponíveis. Também são interessantes os índices de perdas mais significativos de materiais além da composição do RCD (LEITE, 2001 p. 19). Desta forma, o primeiro passo para o gerenciamento adequado dos RCD de Uberaba é identificar a composição dos resíduos que são gerados no município.
Outro ponto importante é o levantamento de todos os aspectos econômicos, sociais e ambientais da cidade. Para que estes levantamentos sejam precisos, é imprescindível uma equipe de profissionais bem capacitada. Esta equipe deve ser acompanhada por pesquisadores e graduandos de diversas áreas do conhecimento, para que as informações obtidas sejam disseminadas e que futuramente sejam publicadas, dando origem a um relatório técnico de alta qualidade para o município. Uma vez caracterizado o RCD do Município e a distribuição deste, deve-se iniciar os estudo das áreas com maior resiliência ambiental para implantação do local de processamento.

A implantação de uma usina de reciclagem de RCD, para Leite (2001), é muito importante e que nesta fase deve ser levado em consideração a capacidade operacional dos equipamentos escolhidos dentre os inúmeros modelos disponíveis no mercado (LEITE, 2001 p. 30). Utilizar plantas fixas para o beneficiamento de RCD é interessante, pois, estas plantas oferecem alguns benefícios como à produção de agregados de melhor qualidade (LEITE, 2001 p. 32). Porém, a utilização de plantas móveis evita o tráfego de caminhões com RCD, uma vez que, não é necessário o seu transporte. Além da implantação das usinas de reciclagem de RCD, é necessário trabalhar com a logística dos agregados produzidos. Nesta logística, trabalhadores informais como carroceiros e catadores devem ser absorvidos, pois, atualmente obtêm sua renda dos resíduos construtivos. A coleta dos RCD na cidade de Uberaba deve ser realizada por caçambas fechadas, uma vez que, os RCD da cidade são em quase sua totalidade oriundos de pequenas obras e em diferentes áreas da cidade, assim inviabilizando o trabalho com plantas móveis de reciclagem de resíduos construtivos. Sendo processador por plantas móveis os RCD do município darão origem a agregados de qualidade que são utilizados na fabricação de manilhas, bancos, sub-base asfáltica, etc. O Poder Público Municipal pode estar utilizando estes agregados em suas obras, tanto no perímetro urbano quanto em área rural além de esses materiais serem revendidos a empresas de construção civil, sendo que o agregado produzido por plantas fixas além de ser de alta qualidade tem um valor competitivo no mercado.

Com a redução dos impactos provocados pelos RCD sem gerenciamento, o Município tem um trabalho

Soc. \& Nat., Uberlândia, ano 24 n. 2, 333-344, mai/ago. 2012 
árduo pela frente que é tentar recuperar as áreas impactadas pela disposição inadequada dos RCD. Merece destaque a área da Pedreira de Léa que está altamente degradada.

Seria executável a implantação do sistema para gerenciamento dos RCD em Uberaba, no entanto foi percebido que não existe interesse político em implantar este sistema. Esta falta de interesse se deve ao fato de que gerenciar resíduos tem menos efeito para conquistar a confiança da população do que ouros tipos de obras geralmente mais visíveis como reforma de praças e paisagismo urbano. Mas este cenário em Uberaba está mudando, pois, a sociedade está tendo uma maior quantidade de informação e tem realizado pressão sobre as lideranças políticas municipais, o que tem gerado discretos resultados. Leite (2001) demonstra os benefícios do gerenciamento adequado de RCD:

A reciclagem é, sem dúvida, a melhor alternativa para reduzir o impacto que o ambiente pode sofrer com o consumo de matéria prima e a geração desordenada de resíduos. Nos últimos anos, a reciclagem de resíduos tem sido incentivada em todo o mundo, seja por questões políticas, econômicas ou ecológicas. A reciclagem de resíduos de construção irá minimizar também os problemas com o gerenciamento dos resíduos sólidos dos municípios. Haverá um crescimento da vida útil dos aterros, diminuição dos pontos de descarte clandestinos e redução dos custos de gerenciamento de resíduos. Adicionalmente, haverá um melhor bem estar social e ambiental (LEITE, 2001 p. 3).

Segundo Mália et. al. (2011), um dos maiores casos de gestão de RCD é a Dinamarca que tem índice de aproveitamento dos RCD de $90 \%$. O motivo por esta elevada taxa de reciclagem deve-se a dois fatores que são: impostos elevados sobre os RCD que não são reciclados e a obrigatoriedade da segregação na fonte. Apesar da precariedade do gerenciamento dos resíduos construtivos, em Uberaba é possível reverter esse quadro e obter percentuais de reaproveitamento dos RCD semelhantes aos da Dinamarca. Tal afirmação se deve ao fato de que a cidade de Uberaba é de médio porte, sendo mais fácil de gerir do que grandes centros urbanos o que levaria a uma política de gestão dos RCD eficiente. O tempo para implantar e ter efetividade o sistema de gerenciamento dos RCD seria de aproximadamente 2 anos (18 meses para construção da central de processamento dos RCD e 6 meses para informar aos cidadãos de Uberaba a nova destinação dos RCD) se não houver falta de recursos e interesse político. No caso de Uberaba não é necessário tempo para elaborar e aprovar lei para gestão dos RCD, uma vez que, já existe a Lei 10.876 (2009) que atende ao sistema de gestão para RCD.

\section{CONCLUSÕES}

1 - Uberaba ainda não tem implementado um sistema de gerenciamento de resíduos da construção e demolição.

2 - Os ecopontos não têm efetividade na captação dos resíduos sólidos.

3- A população de Uberaba não está educada nem sensibilizada ambientalmente quanto à gestão dos resíduos da construção civil.

4- Para promover o gerenciamento dos resíduos construtivos conforme a Resolução 307 (2002) do Conselho Nacional do Meio Ambiente, a cidade de Uberaba precisa investir na fiscalização e sensibilização da população além da sua própria atuação.

5 - A área da Pedreira de Léa precisa ser reabilitada em caráter de urgência.

6- A solução definitiva para os impactos causados pelos resíduos da construção e demolição no $\mathrm{Mu}$ nicípio está na criação de uma planta para reciclagem dos resíduos construtivos, sendo necessária a cobrança de elevadas taxas para aqueles que não promovam a adequada destinação dos resíduos, inclusive sobre o próprio Poder Público Municipal.

\section{REFERÊNCIAS}

BOTTA, A. M. Gerenciamento de resíduos da construção civil em Uberaba-MG. 2011. 20 f. Artigo (Graduação em Direito). Universidade de Uberaba, Uberaba, 2011.

ABNT. Associação Brasileira de Normas Técnicas. NBR-10004 Resíduos Sólidos - Classificação. 2004. 
BRASIL, Resolução CONAMA $n^{\circ} 307$, de 5 de julho de 2002. (Estabelece diretrizes, critérios e procedimentos para a gestão dos resíduos da construção civil).

Lei 4.771/1965, Institui o novo Código Florestal, Disponível em: <http://www.planalto.gov.br/ ccivil_03/leis/L4771.htm>. Acesso em: 02 out. 2011.

. Lei $\mathrm{N}^{\mathrm{o}} 12.305$, de 2 de agosto de 2010. Institui a Politica Nacional de Resíduos Sólidos, altera a Lei no 9.605 , de 12 de fevereiro de 1998; e dá outras providências. . Disponível em: $<\mathrm{http}$ ://www.planalto.gov. br/ccivil_03/ ato2007-2010/2010/lei/112305.htm>. Acesso em: 10 out. 2011.

PINTO, Tarcísio De Paula. Metodologia para a gestão diferenciada de resíduos sólidos da construção urbana. (Tese) Escola Politécnica da Universidade de São Paulo. Disponível em: $<$ http://www.reciclagem.pcc. usp.br/ftp/tese_tarcisio.pdf >. Acesso em: 04 set. 2011.

SCHEIDER, Dan Moche. Deposições Irregulares de Resíduos da Construção Civil na Cidade de São Paulo. (Dissertação de mestrado) Faculdade de Saúde Pública da Universidade de São Paulo. São Paulo, 2003. Disponível em: $<$ http://www.reciclagem.pcc. usp.br/ftp/Schneider_Deposi\%C3\%A7\%C

$3 \%$ B 5 es $\% 20$ Irregu 1 ares $\% 20$ de $\% 20$ $\mathrm{R}$ e s \% C $3 \%$ A D d u o s \% 20 d a $\% 20$ Constru\%C3\%A7\%C3\%A3o.pdf>. Acesso em: 28 ago. 2011.

UBERABA (Município) Lei 10.876/2009, Institui o Sistema municipal para a Gestão Sustentável de Resíduos da Construção Civil e Resíduos Volumosos. Disponível em: < http://www.camarauberaba.mg.gov. br/novo/ >. Acesso em: 21 set. 2011.

ESPINHEIRA, Carlos Geraldo D' Andrea, et al. Encontros e Caminhos: Formação de Educadores Ambientais. Brasília: Ministério do Meio Ambiente, 2007. $352 \mathrm{p}$.

VIEZZER, Moema L. et al. Encontros e Caminhos: Formação de Educadores Ambientais. Brasília: Ministério do Meio Ambiente, 2007. 352 p.
LEITE, Mônica Batista. Avaliação de propriedades mecânicas de concretos produzidos com agregados reciclados de resíduos de construção e demolição (Tese). Programa de pós-graduação em Engenharia Civil. UFRGS. Porto Alegre, 2001. Disponível em: $<$ http://www.reciclagem.pcc.usp.br/ftp/Tese \%20Monica\%20Leite.pdf $>$. Acesso em: 04 set. 2011.

IBGE, Minas Gerais: Uberaba. Disponível em: $<$ http://www.ibge.gov.br/cidadesat /topwindow.htm?1>. Acesso em: 28 jul. 2011.

CARELI, Élcio Duduchi. A Resolução CONAMA 307/2002 e as novas condições para gestão dos resíduos de construção e demolição. Dissertação (Mestrado) - Curso de Tecnologia, Departamento de Resíduos Sólidos Urbanos, Centro Estadual de Educação Tecnológica Paula Souza, São Paulo, 2008. 155 f. Disponível em: $<\mathrm{http}: / /$ www.centropaulasouza.sp.gov. br/Posgraduacao/Trabalhos/Dissertacoes/DM_elcio-duduchi-careli.pdf $>$. Acesso em: 02 jul. 2011.

EVANGELISTA, Patricia Pereira de Abreu; COSTA, Dayana Bastos; COSTA, Dayana Bastos. Alternativa sustentável para destinação de resíduos de construção classe A: sistemática para reciclagem em canteiros de obras. Ambiente Construido. Porto Alegre. Vol.10, n.3. 2010, p.23-40. Disponível em: <http://seer.ufrgs.br/ ambienteconstruido/search/advanced

Results>. Acesso em set. 2011.

MÁLIA, Miguel. et. al. Indicadores de resíduos de construção e demolição para construções residenciais novas. Ambiente Construido, Porto Alegre, v. 11, $\mathrm{n}$. 3, 2010. p.117-130. Disponível em: <http://seer.ufrgs. br/ambienteconstruido /issue/view/797>. Acesso em out. 2011.

SOUZA, Márcia I. B.; SEGANTINI, Antonio A. S. e PEREIRA, Joelma A.. Tijolos prensados de solo-cimento confeccionados com resíduos de concreto. Rev. bras. eng. agríc. ambient. [online]. 2008, vol.12, n.2, pp. 205-212. ISSN 1807-1929. Disponível em : http:// dx.doi.org/10.1590/S1415-43662008000200014., acesso em outubro de 2011.

Soc. \& Nat., Uberlândia, ano 24 n. 2, 333-344, mai/ago. 2012 